Research Article

\title{
Double Burden of Malnutrition: Evidence from a Selected Nigerian Population
}

\author{
Emmanuel O. Alamu, ${ }^{1,2}$ Toluwalope E. Eyinla, ${ }^{2,3}$ Rasaki A. Sanusi, ${ }^{3}$ \\ and Busie Maziya-Dixon (iD) ${ }^{2}$ \\ ${ }^{1}$ Food and Nutrition Sciences Laboratory, International Institute of Tropical Agriculture (IITA), Southern Africa Hub, \\ P.O. Box 310142, Chelston, Lusaka, Zambia \\ ${ }^{2}$ Food and Nutrition Sciences Laboratory, International Institute of Tropical Agriculture (IITA), PMB 5320, Oyo Road, Ibadan, \\ Oyo State, Nigeria \\ ${ }^{3}$ Department of Human Nutrition, College of Medicine, University of Ibadan, Ibadan, Oyo State, Nigeria
}

Correspondence should be addressed to Busie Maziya-Dixon; b.maziya-dixon@cgiar.org

Received 10 February 2020; Revised 19 July 2020; Accepted 18 August 2020; Published 1 September 2020

Academic Editor: Jos Mar A. Huerta

Copyright $\odot 2020$ Emmanuel O. Alamu et al. This is an open access article distributed under the Creative Commons Attribution License, which permits unrestricted use, distribution, and reproduction in any medium, provided the original work is properly cited.

\begin{abstract}
Indices reflecting the double burden of malnutrition in sub-Saharan Africa are increasing. Evidence to support this claim in households of Africa's most populous country-Nigeria-is scant. This study, therefore, presents results from a study of mother-child pairs sampled from Akwa Ibom State in the southern region of Nigeria. Anthropometric measures for 660 mother-child pairs were collected according to standard procedures. Indices were expressed as the standard deviation of units from the median for the reference group. Chi-square analysis was used to test significant differences in proportion, and $p<0.05$ was taken as significant. A total of $37.4 \%$ of the children were stunted out of which $19.8 \%$ were moderately stunted, and $17.6 \%$ were severely stunted. Prevalence of wasting was $13.1 \%, 6.2 \%$ were moderately wasted, and $6.9 \%$ were severely wasted. Mean maternal body mass index was $(23.54 \pm 4.60) \mathrm{kgm}^{2} .9 .0 \%$ were underweight mothers, $23.2 \%$ were overweight, and $9.3 \%$ were obese. The co-existence of undernutrition among children and overnutrition in women of child-bearing age is prevalent in this population. We recommend that more effort be placed on active nutrition surveillance to ascertain malnutrition prevalence and periodically reassess priority challenges.
\end{abstract}

\section{Introduction}

One of the most critical global disease burdens is malnutrition presenting as deficiencies and excess [1]. This burden accounts for at least 9 million deaths per year in children less than five years of age [2]. It is a significant public health problem, most notably in developing countries [3-5] where $90 \%$ of the world's undernourished children live. More troubling is the co-existence of both undernutrition and overnutrition in the same population, which is currently becoming a significant health problem globally [5]. This trend is more challenging in developing countries that are still tackling endemic undernutrition causes and effects $[6,7]$. Poor nutrition during the early formative years has been implicated to result in significant morbidity and mortality and delayed mental and motor developments [8]. In the long term, it has been linked to impairments of intellectual performance, work capacity, reproductive outcomes, and overall health [9]. Unfortunately, a significant cause is poor maternal nutritional status, which can harm the offspring, thus leading to a vicious cycle of malnutrition from one generation to another [3]. Thus, the nutritional status of mothers is essential both for her health and that of her baby. The consequences of poor maternal nutritional status are reflected in high infant and maternal morbidity and mortality, as described by Black et al. [3], Elshibly and Schmalisch [10], and Ugwa [11]. Nutritional deficiencies could manifest as either protein-energy malnutrition or micronutrient malnutrition (hidden hunger). Hidden hunger is much more difficult and expensive to assess. 
However, anthropometric measurements are practical and realistic tools for rapid assessment of the nutritional status of populations in developing countries and have been adapted in assessing both women and children [11-13]. Evidence has been established proving that the effects of undernutrition and overnutrition occurring concurrently in an individual, household, or population can be damaging [14]. Its occurrence in sub-Saharan Africa has been reviewed [3]; however, the evidence is still lacking from Africa's most populous country-Nigeria. In 2001-2003, the Nigerian food consumption and nutrition survey revealed $42 \%$ stunting among children under the age of 5 years, underweight was $25 \%$, and wasting was $9 \%$ [15].

Similarly, according to the 2008 Nigerian National Demographic and Health Survey, $41 \%$ of Nigerian children less than five years were stunted, $23 \%$ were underweight, and 14\% were wasted [16] (NDHS 2008). The NDHS 2013 [17] survey reflected a mild drop in these indices (especially stunting) but still gave reports of nutritional status that signify public health challenges. Scant studies have probed this challenge in mother-child pairs in Nigeria. A recent study examined the underlying causal factors of malnutrition in obese mother/stunted child pairs [18]. A review of the literature reveals several studies around Nigeria have investigated the challenge of protein-energy malnutrition in children [18-22] and women [23-25]. A study [26] presented results of nutritional parameters in mother-child pairs in Akwa Ibom State, Nigeria, with the sole aim of probing vitamin A intake to justify the introduction of biofortified cassava (rich in carotenoids which is a vitamin A precursor) considering that the state has the highest consumption of Nigeria's chief carbohydrate crop-cassava. While this study expatiated on hidden hunger rates in the selected population, anthropometric information was not critically reported in this population. A closer look into these anthropometric indicators is justified by results of the Nigeria demographic health surveys in the past decade that have established that women in the southern regions were having highest rates of overnutrition which had increased from $26.7 \%$ in 2008 [16] to $32.05 \%$ in 2013 [17]. As have been found in similar populations [7, 18], these increases suggest that in the same household where the child may be undernourished, the mother (or primary caregiver) may be experiencing another form of malnutrition. This study was thus conducted to assess anthropometric indices among women of child-bearing age and children 6-59 months old in Akwa Ibom State, South-South region, Nigeria.

\section{Methodology}

2.1. Study Design. This was a descriptive cross-sectional study to assess anthropometric indices of women of childbearing age and children aged between 6 and 59 months. It was conducted alongside the study on vitamin A status of women of child-bearing age in Akwa Ibom State, Nigeria.

2.2. Study Location. Akwa Ibom State, which is located in the South-South geopolitical zone and the humid forest agroecological zone, was selected as the project state. Earlier surveys had established that the state has the highest consumption of cassava and a high prevalence of vitamin A deficiency.

2.3. Sample Size Estimation. The estimation of sample size for this study was based on the prevalent data on vitamin A deficiency (VAD) and iron and zinc deficiencies obtained for the state from the National Nutrition survey [15]. The prevalence of wasting, stunting, and underweight obtained from the National Demographic and Health Survey [16] was included in the estimation of sample size. The sample size was calculated based on the following criteria and assumptions:

(i) The confidence level of 93.5 (precision of 6.5\%)

(ii) Power of $80 \%$

(iii) Estimated malnutrition among children of $30 \%$

(iv) A design effect of 2.5

(v) The individual response rate of $85 \%$

(vi) Seven individuals per household on average

(vii) Sixteen percent of the population being children of 6-59 months of age

(viii) A sample size of 660 households was estimated

Thus, a total of 660 households with women of childbearing age and children of 6-59 months of age were selected for the study.

2.4. Sampling Procedures. The sample was selected using a multistage selection scheme consisting of three levels: selection of local government areas (LGAs), enumeration areas (EAs), and households. Akwa Ibom State has 31 LGAs, made up of 16 rural, 5 urban, and 10 periurban areas. In Nigeria, the current official designation of rural, urban, and periurban is based mainly on population. According to the National Population Commission of Nigeria, a community with less than 5,000 people is regarded as rural, between 5,000 and 20,000 people is regarded as periurban, and above 20,000 is regarded as urban. Since malnutrition is prevalent in both urban and rural centres and dietary habits cut across all sectors of urbanization, ten (10) LGAs were selected using the probability proportionate to size, such that the likelihood of an LGA being selected was proportionate to its size. This resulted in the selection of 5 rural, 1 urban, and 4 periurban areas. A random selection of three EAs within each LGA was made. Therefore, a total of 30 EAs were sampled. At least 22 households were sampled randomly at the community level from each EA totalling 660 households.

2.5. Anthropometry. Anthropometric indicators for women and children were collected in the study to provide outcome measures for nutritional status. Weight and height for both mothers and children were collected according to standard procedures, which included tared weighing procedure and length (recumbent) measurement for children under 24 
months, while height measurement (standing) was carried out for children above 2 years and their mothers [16].

2.6. Data Processing and Statistical Analysis. Data entry was done using MS Access and MS Excel. Data verification, screening, and editing were carried out to ensure that the entry errors were corrected. Double entered data were compared using the compare procedure of the Statistical Analysis System (SAS) to identify erroneously recorded data which usually cannot be easily verified or corrected. Weight and height values were used to calculate and classify body mass index (BMI) for mothers based on the World Health Organization classifications. Mothers within the teenage category were classified using WHO-Anthro Plus software, 2006, using the BMI-for-age classification [27]. Height-forage, weight-for-age, and weight-for-height were determined using WHO-Anthro Plus software, 2006. The results obtained were compared with reference values from the population of well-nourished children. Indices were expressed as the standard deviation of units from the median for the reference group.

Outlier values such as implausible values for anthropometric indices were excluded from the dataset. This accounts for variation in reported frequencies. Frequency of each variable was conducted to ensure that values are within the acceptable range. Essential basic descriptive statistics and plots on distribution were conducted using SAS version 9.2, Cary, NC, USA. The chi-square test tested the significance of differences in proportion, and $p<0.05$ was taken as significant.

2.7. Ethics Approval and Informed Consent. Ethical clearance was obtained through the Nutrition Division in the National Health Research Ethics committee based in the Federal Ministry of Health, Abuja. Ethical approval was also obtained from Akwa Ibom State Research Ethics committee in the Ministry of Health. Written informed consent was obtained from the women who participated in the study after the study objectives had been explained.

\section{Results}

As presented in Table 1, a total of 547 children had data on age and mean \pm standard deviation. The mean age among children was $30.84 \pm 13.02$ months. The number of boys was 273 with a mean age of $31.61 \pm 13.38$ months while the girls numbered 274, with a mean age of $30.08 \pm 12.62$ months. There was no significant difference in the mean age between boys and girls $(p=0.17)$. Mean weight among children was $12.70 \pm 3.78 \mathrm{~kg}$, that of boys was $13.03 \pm 3.76 \mathrm{~kg}$, and girls had a mean weight of $12.36 \pm 3.76 \mathrm{~kg}$. There was a significant difference in mean weight between boys and girls $(p=0.041)$. Five hundred and forty-three children had data on height, and the mean value was $87.28 \pm 13.39 \mathrm{~cm}$. Mean height for boys was $88.29 \pm 14.57 \mathrm{~cm}$ and that of girls was $86.28 \pm 12.04 \mathrm{~cm}$. As presented in Table 2, a total of five hundred and ninety-six children were assessed for heightfor-age; of these, 295 (49.5\%) were boys, and 301 (50.5\%) were girls. Three hundred and seventy-three $(62.9 \%)$ children had normal height-for-age; of these, 183 (30.7\%) were boys, and $190(31.9 \%)$ were girls. The total prevalence of stunting among children was 223 (37.4\%); of these, 112 (18.6\%) were boys, and 111 (18.7\%) were girls. Prevalence of mild/moderate stunting was 118 (19.8\%), and that of severe stunting was $105(17.6 \%)$. There was no significant difference in stunting between boys and girls. A total of 593 children were assessed for weight-for-age; of these, 294 (49.6\%) were boys, and 299 (50.4\%) were girls. The total prevalence of underweight among children was $108(18.2 \%)$, comprising $67(11.3 \%)$ moderate underweight and 41 (6.9\%) severe underweight. Of the total number of underweight children, $53(9.0 \%)$ were boys, and 55 (9.2\%) were girls. There were no significant differences in underweight between boys and girls $(p>0.05)$. A total of five hundred and fifty-one children were assessed for weight-for-height. Results showed that a total of $72(13.1 \%)$ of the children were wasted. Of these, 34 (6.2\%) were moderately wasted, and 38 (6.9\%) were severely wasted. Again, there was no significant difference between boys and girls in wasting. As presented in Table 3, the mean age among mothers was $27.28 \pm 6.85$. Mean weight and height were $58.43 \pm 12.05 \mathrm{~kg}$ and $157.52 \pm 6.56 \mathrm{~cm}$, respectively. Anthropometric data from 620 women were used to calculate maternal BMI. Highest body mass index (BMI) was $45.45 \mathrm{~kg} / \mathrm{m}^{2}$; the lowest BMI was $14.55 \mathrm{~kg} / \mathrm{m}^{2}$, and the mean BMI was $23.54 \pm 4.60 \mathrm{~kg} / \mathrm{m}^{2}$. A total of $58.71 \%$ of the women had BMI values in the normal range. About $55(8.87 \%)$ of the respondents were underweight, and $142(23.39 \%)$ were overweight. Also, 57 (9.03\%) were obese with a BMI higher than $30 \mathrm{~kg} / \mathrm{m}^{2}$. Table 4 presents the crosstabulation of mothers' BMI status in comparison with children's anthropometric indices. The mother-child comparison showed that 105 (16.94\%) moderately stunted and 94 (15.16\%) severely stunted children had $45(8.25 \%)$ and 18 (2.90\%) overweight or obese mothers, respectively. Among the 44 (7.13) children who were severely underweight, only 11 (1.78) and $4(0.65)$ had overweight and obese mothers, respectively. For the weight-for-height index, 30 (4.89\%) experiencing mild wasting and $37(6.04 \%)$ of the children who were severely wasted had $15(2.45 \%)$ overweight and 7 $(1.14 \%)$ obese mothers. There was no significant $(p>0.055)$ relationship between mother's BMI and any of the children's anthropometric indices.

\section{Discussion}

This study thus presents information on the occurrence of double burden malnutrition after assessing anthropometric assessments in mother-child pairs living in Akwa Ibom State. The result of this study indicated a high prevalence of stunting and wasting among the children in Akwa Ibom State. The underweight levels were, however, of medium severity. The stunting levels in this study were lower than a report [22] in which children living in Makurdi, a northcentral area of the country, were surveyed. This stunting level in this study is, however, higher than those reported by literature $[25,28]$ from the southwestern part of the country. The rural study location may have contributed to this 
TABLE 1: Age and anthropometric information of children of 6-59 months.

\begin{tabular}{|c|c|c|c|c|c|c|c|}
\hline & \multicolumn{2}{|r|}{ Total } & \multicolumn{2}{|r|}{ Boys } & \multicolumn{2}{|r|}{ Girls } & \multirow{2}{*}{$p$ value } \\
\hline & No & Mean \pm SD & No & Mean \pm SD & No & Mean \pm SD & \\
\hline Age (months) & 547 & $30.84 \pm 13.02$ & 273 & $31.61 \pm 13.38$ & 274 & $30.08 \pm 12.62$ & 0.170 \\
\hline Weight (kg) & & $12.70 \pm 3.78$ & & $13.03 \pm 3.76$ & & $12.36 \pm 3.76$ & $0.041^{*}$ \\
\hline Height $(\mathrm{cm})$ & 543 & $87.28 \pm 13.39$ & 273 & $88.29 \pm 14.57$ & 270 & $86.28 \pm 12.04$ & 0.079 \\
\hline
\end{tabular}

*Significance at $p<0.05$.

TABLE 2: Nutritional anthropometry: height-for-age, weight-for-age, and weight-for-height for children.

\begin{tabular}{|c|c|c|c|c|c|}
\hline Indices & Sex & -2 to $+2 \mathrm{SD}(\mathrm{N} \%)$ & $\leq-2$ to $-3 \mathrm{SD}(\mathrm{N} \%)$ & $<-3 \mathrm{SD}(\mathrm{N} \%)$ & Total $(\mathrm{N} \%)$ \\
\hline \multirow{3}{*}{ Height-for-age (stunting) } & Boys & $183(30.7)$ & $61(10.2)$ & $51(8.6)$ & $295(49.5)$ \\
\hline & Girls & $190(31.9)$ & $57(9.6)$ & $54(9.1)$ & $301(50.5)$ \\
\hline & Total & $373(62.9)$ & $118(19.8)$ & $105(17.6)$ & $596(100)$ \\
\hline \multirow{3}{*}{ Weight-for-age (underweight) } & Boys & $241(40.6)$ & $33(5.6)$ & $20(3.4)$ & $294(49.6)$ \\
\hline & Girls & $244(41.1)$ & $34(5.7)$ & $21(3.5)$ & $299(50.4)$ \\
\hline & Total & $485(81.8)$ & $67(11.3)$ & $41(6.9)$ & $593(100)$ \\
\hline \multirow{3}{*}{ Weight-for-height (wasting) } & Boys & $234(42.5)$ & $18(3.3)$ & $16(2.9)$ & $268(48.6)$ \\
\hline & Girls & $245(44.5)$ & $16(2.9)$ & $22(4.0)$ & $283(51.4)$ \\
\hline & Total & $479(86.9)$ & $34(6.2)$ & $38(6.9)$ & $551(100)$ \\
\hline
\end{tabular}

$>-2 \mathrm{SD}$ to $+2 \mathrm{SD}=$ normal $\leq-2$ to $-3 \mathrm{SD}=$ mild $/$ moderate $;<-3 \mathrm{SD}=$ severe.

Table 3: Age and anthropometric information of mothers.

\begin{tabular}{lcccc}
\hline Variable & $N$ & Mean \pm SD & Minimum & Maximum \\
\hline Age (years) & 644 & $27.28 \pm 6.85$ & 14 & 50 \\
Weight $(\mathrm{kg})$ & 638 & $58.43 \pm 12.05$ & 33 & 113.30 \\
Height $(\mathrm{cm})$ & 641 & $157.52 \pm 6.56$ & 140 & 191.00 \\
Body mass index $\left(\mathrm{kgm}^{2}\right)$ & 635 & $23.54 \pm 4.60$ & 14.55 & 45.45 \\
\hline
\end{tabular}

TABLE 4: Anthropometric categories of mothers with their children.

\begin{tabular}{|c|c|c|c|c|c|c|}
\hline Indices & & Normal & $\begin{array}{l}\text { Thin/under } \\
\text { weight }\end{array}$ & Overweight & Obese & Total \\
\hline \multirow{4}{*}{ Stunting $(p=0.410)$} & Normal & $247(39.84)$ & $36(5.81)$ & $100(16.13)$ & $38(6.13)$ & $421(67.9)$ \\
\hline & Mild/moderate & $69(11.13)$ & $7(1.13)$ & $19(3.06)$ & $10(1.61)$ & $105(16.94)$ \\
\hline & Severe & $48(7.74)$ & $12(1.94)$ & $26(4.19)$ & $8(1.29)$ & $94(15.16)$ \\
\hline & Total & $364(58.71)$ & $55(8.87)$ & $145(23.39)$ & $56(9.03)$ & $620(100)$ \\
\hline \multirow{4}{*}{ Underweight $(p=0.613)$} & Normal & $309(50.08)$ & $42(6.81)$ & $125(20.26)$ & $45(7.29)$ & $521(84.44)$ \\
\hline & Mild/moderate & $30(4.86)$ & $7(1.13)$ & $9(1.46)$ & $6(0.97)$ & $52(8.43)$ \\
\hline & Severe & $23(3.73)$ & $6(0.97)$ & $11(1.78)$ & $4(0.65)$ & $44(7.13)$ \\
\hline & Total & $362(58.67)$ & $55(8.91)$ & $145(23.5)$ & $55(8.91)$ & $617(100)$ \\
\hline \multirow{4}{*}{ Wasting $(p=0.829)$} & Normal & $321(52.37)$ & $47(7.67)$ & $130(21.21)$ & $48(7.83)$ & $546(89.07)$ \\
\hline & Mild/moderate & $16(2.61)$ & $2(0.33)$ & $9(1.47)$ & $3(0.49)$ & $30(4.89)$ \\
\hline & Severe & $22(3.59)$ & $5(0.82)$ & $6(0.98)$ & $4(0.65)$ & $37(6.04)$ \\
\hline & Total & $359(58.56)$ & $54(8.81)$ & $145(23.65)$ & 55 (8.97) & $613(100)$ \\
\hline
\end{tabular}

disparity. These stunting values presented in this study are consistent with national estimates of stunted children in Nigeria [17]. Prevalence of underweight among children was comparable to results reported in the literature [21, 29]. The wasting levels of children in this study can be considered to be of public health significance which suggests an occurrence of severe acute illness. There was no significant difference in stunting, underweight, and wasting between boys and girls observed in this study. Several factors can be implicated as contributing to child undernutrition [30]. The Nigerian Demographic Health Survey has described these factors to include child sex, age, location, and socioeconomic status of the household which consists of factors such as parents' occupations and education with particular reference to maternal education [16]. Several other factors contributing to the high prevalence of undernutrition among children could include severe food shortage or suboptimal complementary feeding practices, and inadequate household sanitary facilities which can lead to illnesses and growth faltering [28]. Among Ethiopian children, Tessema et al. [31] stated that the prevalence of undernutrition was different across age groups of the children, which implies that each 
stage of growth has its peculiarity. The mean height of the women falls within the short maternal height range described by the WHO collaborative study [27, 32]. It is vital since it can be used to identify women with obstetric risks and predict reproductive outcomes [33]. Even though the maternal undernutrition in this study is low, undernourishment in women is always a situation of public health concern [34]. The more prevalent form of malnutrition among women in this study was overweight, which can be classified as a problematic situation of public health significance.

In comparison to national estimates, the values in this study confirm a rise in the prevalence of overweight/obese women of child-bearing age [17] which could indicate suggestions of nutrition transition $[7,35]$ which could have both short- and long-term implication for maternal and child health [10, 11, 36, 37]. If the whole population is thus considered, there is a high prevalence of undernourished children and overweight mothers which indicates the existence of a double burden of malnutrition in the same population. This observation is similar to findings locally [18] and globally $[7,14]$.

Contrary to usual expectations that in low-middle income settings, malnutrition is unidirectional (undernourishment), this study thus asserts that it can be in two directions. This occurrence even raises the questions of the possibility of hidden hunger being present in the same population. At the household level, this occurrence is not apparent and expectedly was not statistically significant as presented in the results. However, the existence at population level confirms reports by Popkin et al. [7, 38] who explained that variations still exist in the severity across the nations of the world. However, the existence is real, and interventions to reduce the burden should be expedited.

\section{Conclusion and Recommendation}

Prevalence of malnutrition expressed as stunting, underweight, and wasting is high among the children involved in this study, so is maternal overnutrition which is prevalent among mothers. There was no significant difference in stunting, underweight, and wasting between boys and girls. This prevalence indicates that in the same population, the presence of different forms of malnutrition exists. However, this trend is particularly worthy of note since Nigeria is still grappling with the challenges of undernutrition, and most of the interventions are usually focused in this direction. The evidence presented gives support to the growing list of reports that the existence of binary forms of malnutrition is manifesting at the household level, especially in areas of low economic status. Also, it provides a basis for strengthening any existing intervention to eradicate factors associated with double malnutrition, specifically in the South-South region and generally Nigeria. Besides, there was no relationship between the mother's BMI and any of the children's anthropometric indices.

This report, therefore, recommends that more effort be placed on active nutrition surveillance to ascertain the prevalence and periodically reassess priority challenges. We also recommend that nutrition education in the areas of healthy eating for weight control for women and interventions on infant and young child care be implemented and strengthened. These interventions should be carried out synergetically and not in parallel forms.

\section{Data Availability}

The data used to support the findings of this study are available from the corresponding author upon request.

\section{Disclosure}

HarvestPlus and its partners are working towards biofortification of significant crops with increased levels of provitamin A to address vitamin A deficiencies (VADs) in developing countries.

\section{Conflicts of Interest}

The authors declare that they have no conflicts of interest.

\section{Acknowledgments}

The authors acknowledge the HarvestPlus programme and Ministry of Health, Akwa Ibom State, Nigeria, for providing technical assistance and approval of ethical clearance, respectively. The support of CRP Agriculture for Nutrition and Health $(\mathrm{A} 4 \mathrm{NH})$ is also acknowledged. Also, special thanks to Mr. Ofodile Sam (IITA-Nigeria) for data analysis, all the project staff who mobilized communities for the study to be conducted, and the entire paticipants of the study.

\section{References}

[1] M. Ezzati, A. D. Lopez, A. Rodgers, S. Vander Hoorn, and C. J. Murray, "Selected major risk factors and global and regional burden of disease," The Lancet, vol. 360, no. 9343, pp. 1347-1360, 2002.

[2] UNICEF, United Nations Children's Fund. Progress for Children: A World Fit for Children Statistical Review, UNICEF, New York, NY, USA, 2007.

[3] R. E. Black, L. H. Allen, Z. A. Bhutta et al., "Child undernutrition study group. maternal and child undernutrition: global and regional exposures and health consequences," Lancet.vol. 371, no. 9608, 2008.

[4] Z. A. Bhutta, T. Ahmed, R. E. Black et al., "What works? Interventions for maternal and child undernutrition and survival," Lancet, vol. 371, no. 9610, 2008.

[5] Department of Nutrition for Health and Development (NHD), World Health Organization, Double Burden, https:// www.who.int/nutrition/double-burden-malnutrition/en/.

[6] G. Kennedy, G. Nantel, and P. Shetty, "The double burden of malnutrition: case studies from six developing countries," Nutrition Planning, Assessment And Evaluation Service, http:// www.fao.org/docrep/pdf/009/a0442e/a0442e00.pdf, Food and Agriculture Organization of the United Nations, Rome, Italy, 2007, http://www.fao.org/docrep/pdf/009/a0442e/a0442e00.pdf.

[7] B. M. Popkin, L. S. Adair, and S. W. Ng, "Global nutrition transition and the pandemic of obesity in developing countries," Nutrition Reviews, vol. 70, no. 1, pp. 3-21, 2012. 
[8] R. Slater, S. Ashley, M. Tefera, M. Buta, and D. Esubalew, "PSNP policy, programme and institutional linkages," ODI/ IDL Group/Indak, Addis Ababa, Ethiopia, 2006, https://www. odi.org/sites/odi.org.uk/files/odi-assets/publicationsopinion-files/3964.pdf.

[9] K. G. Dewey and K. Begum, "Long-term consequences of stunting in early life," Maternal \& Child Nutrition, vol. 7, pp. 5-18, 2011.

[10] E. M. Elshibly and G. Schmalisch, "The effect of maternal anthropometric characteristics and social factors on gestational age and birth weight in Sudanese newborn infants," BMC Public Health, vol. 8, no. 1, p. 244, 2008.

[11] E. A. Ugwa, "Maternal anthropometric characteristics as determinants of birth weight in North-West Nigeria: a prospective study," Nigerian Journal of Basic Clinical Sciences, vol. 11, no. 1, 2014.

[12] A. Chiabi, P. F. Tchokoteu, V. Takou, F. Fru, and F. Tchouine, "Anthropometric measurements of children attending a vaccination clinic in Yaounde, Cameroon," African Health Sciences, vol. 8, no. 3, pp. 174-179, 2008.

[13] J. L. Santos, J. Kain, P. Dominguez-Vásquez et al., "Maternal anthropometry and feeding behavior toward preschool children: association with childhood body mass index in an observational study of Chilean families," International Journal of Behavioral Nutrition and Physical Activity, vol. 6, no. 1, p. 93, 2009.

[14] R. Shrimpton and C. Rokx, The Double Burden of Malnutrition: A Review of the Global Evidence. Health, Nutrition and Population Discussion Paper, World Bank, Washington, DC, USA, 2012, https://openknowledge.worldbank.org/handle/ $10986 / 27417$.

[15] B. Maziya-Dixon, I. O. Akinyele, E. B. Oguntona, S. Nokoe, and E. Harris, Nigeria Food Consumption and Nutrition Survey 2001-2003 Summary, IITA, Ibadan, Nigeria, 2004.

[16] NDHS National Population Commission (NPC), [Nigeria] and ICF Macro. Nigeria Demographic and Health Survey, National Population Commission and ICF Macro, Abuja, Nigeria, 2008, http://www.nigerianstat.gov.ng/nada/index. $\mathrm{php} /$ catalog/27/download/91.

[17] NDHS National Population Commission (NPC), [Nigeria] and ICF International. Nigeria Demographic and Health Survey, NPC and ICF International, Abuja, Nigeria, 2013, https://dhsprogram.com/pubs/pdf/fr293/fr293.pdf.

[18] O. S. Idowu, O. S. Comfort, A. A. Wasiu, and O. O. Ibiyemi, "Co-existence of maternal overweight and obesity with childhood undernutrition in rural and urban communities of Lagos State, Nigeria," Acta Bio Medica: Atenei Parmensis, vol. 90, no. 3, pp. 266-274, 2020.

[19] S. I. Odunayo and A. O. Oyewole, "Risk factors for malnutrition among rural Nigerian children," Asia Pacific Journal of Clinical Nutrition, vol. 15, no. 4, 2006.

[20] R. H. Glew, C. A. Conn, R. Bhanji, P. Calderon, C. Barnes, and D. J. Vanderjagta, "Survey of the growth characteristics and body composition of Fulani children in a rural hamlet in northern Nigeria," Journal of Tropical Pediatrics, vol. 49, no. 5, pp. 313-322, 2003.

[21] U. F. Ekpo, A. M. Omotayo, and M. A. Dipeolu, "Prevalence of malnutrition among settled pastoral Fulani children in Southwest Nigeria," BMC Research Notes, vol. 1, no. 1, p. 7, 2008.

[22] D. T. Goon, A. L. Toriola, B. S. Shaw et al., "Anthropometrically determined the nutritional status of urban primary school children in Makurdi, Nigeria," BMC Public Health, vol. 11, no. 1, p. 769, 2011.
[23] H. N. Ene-Obong, G. I. Enugu, and A. C. Uwaegbute, "Determinants of health and nutritional status of rural Nigerian women," Journal of Health, Population and Nutrition, vol. 1, no. 3, pp. 20-30, 2001.

[24] P. O. Ukegbu, A. C. Uwaegbute, I. I. Ijeh, and J. U. Anyika, "Influence of maternal anthropometric measurements and dietary intake on lactation performance in Umuahia Urban Area, Abia State, Nigeria," Nigerian Journal of Nutritional Sciences, vol. 33, no. 2, pp. 31-39, 2012.

[25] I. O. Senbanjo, I. O. Olayiwola, W. A. O. Afolabi, and O. C. Senbanjo, "Maternal and child under-nutrition in rural and urban communities of Lagos State, Nigeria: the relationship and risk factors," BMC Research Note, vol. 6, no. 1, p. 286, 2013.

[26] F. F. De Moura, M. Moursi, A. Lubowa et al., "Cassava intake and vitamin A status among women and preschool children in Akwa-Ibom, Nigeria," PLoS One, vol. 10, no. 6, Article ID e0129436, 2015.

[27] World Health Organization, Maternal Anthropometry and Pregnancy Outcomes: A WHO Collaborative Study, World Health Organization, Geneva, Switzerland, 1995.

[28] Q. J. Akorede and O. M. Abiola, "Assessment of nutritional status of under-five children in akure south local Government, Ondo state Nigeria," International Journal of Research and Reviews in Applied Sciences, vol. 14, no. 3, pp. 671-681, 2013.

[29] M. B. Fetuga, T. A. Ogunlesi, A. F. Adekanmbi, and A. D. Alabi, "Nutritional status of semi-urban Nigerian school children using 2007 WHO reference population," West African Journal of Medicine, vol. 30, no. 5, pp. 331-336, 2011.

[30] S. Nandy, M. Irving, D. Gordon, S. V. Subramanian, and G. D. Smith, "Poverty, child undernutrition and morbidity: new evidence from India," Bulletin of the World Health Organization, vol. 83, no. 3, pp. 210-216, 2005.

[31] M. Tessema, T. Belachew, and G. Ersino, "Feeding patterns and stunting during early childhood in rural communities of Sidama, South Ethiopia," Pan African Medical Journal, vol. 14, no. 1, 2013.

[32] M. T. Ververs, A. Antierens, A. Sackl, N. Staderini, and V. Captier, "Which anthropometric indicators identify a pregnant woman as acutely malnourished and predict adverse birth outcomes in the humanitarian context?" PLoS Currents, vol. 5, 2013.

[33] S. V. Subramanian, E. Özaltin, and J. E. Finlay, "Height of nations: a socioeconomic analysis of cohort differences and patterns among women in 54 low-to middle-income countries," PLoS One, vol. 6, no. 4, Article ID e18962, 2011.

[34] S. N. Chinedu and O. C. Emiloju, "Underweight, overweight and obesity amongst young adults in Ota, Nigeria," Journal of Public Health Epidemiology, vol. 6, no. 7, pp. 236-238, 2014.

[35] A. M. Prentice, "The double burden of malnutrition in countries passing through the economic transition," Annals of Nutrition Metabolism, vol. 72, no. 3, pp. 39-46, 2018.

[36] A. D. Stein, A. M. Thompson, and A. Waters, "Childhood growth and chronic disease: evidence from countries undergoing the nutrition transition," Maternal and Child $\mathrm{Nu}$ trition, vol. 1, no. 3, pp. 177-184, 2005.

[37] Z. B. Yu, S. P. Han, G. Z. Zhu et al., "Birth weight and subsequent risk of obesity: a systematic review and metaanalysis," Obesity Reviews, vol. 12, no. 7, pp. 525-542, 2011.

[38] B. M. Popkin, C. Corvalan, and L. M. Grummer-Strawn, "Dynamics of the double burden of malnutrition and the changing nutrition reality," The Lancet, vol. 395, no. 10217, pp. 65-74, 2020. 